\title{
SPECIFIC MAGNETIC PROPERTIES OF THE Eu-DOPED PbTe SINGLE CRYSTALS
}

\author{
D. M. Zayachuk ${ }^{1}$, V. I. Mikityuk ${ }^{2}$, A. V. Pashuk ${ }^{1}$, \\ V. V. Shlemkevych ${ }^{2}$, K. S. Ulyanitsky ${ }^{2}$, D. Kaczorowski ${ }^{3}$ \\ ${ }^{1}$ Lviv Polytechnic National University, 12, Bandera St., 79013 Lviv, Ukraine \\ ${ }^{2}$ Yuriy Fedkovych Chernivtsy National University, 2, Kotsyubynsky St., 58012 Chernivtsi, Ukraine \\ ${ }^{3}$ Institute of Low Temperature and Structure Research, \\ Polish Academy of Sciences, 50-950 Wroctaw 2, P. O. Box 1410, Poland \\ e-mail: zayachuk@polynet.lviv.ua
}

(Received August 24, 2011; received in final form April 9, 2012)

\begin{abstract}
The magnetization $M$ under temperature $1.72 \mathrm{~K}$ in the range of magnetic field $B 0-5 \mathrm{~T}$ and the magnetic susceptibility (MS) $\chi$ under magnetic field $0.1 \mathrm{~T}$ in the temperature range $1.7-400 \mathrm{~K}$ of the powder and crystal PbTe:Eu samples fabricated from the bulk and surface layers of the doped ingots grown from the melt by the Bridgman method are investigated. Specific magnetic properties in the Eu-doped $\mathrm{PbTe}$ single crystals are revealed: (i) the strong differences between the magnetization and MS of the surface and bulk of the PbTe:Eu doped ingots; (ii) strong paramagnetism of the surface layers practically independent of $T$ in the temperature range over $30 \mathrm{~K}$; (iii) the principal discrepancies between the temperature dependences of MS of the crystal matrix of powder and crystal doped samples. Possible mechanisms of the appearance of the mentioned peculiarities of the magnetic properties of different powder and crystal samples are analyzed.
\end{abstract}

Key words: $\mathrm{PbTe}, \mathrm{Eu}$, rare-earth impurities, magnetic properties, distributions.

PACS number(s): 75.20.-g, 75.30.Hx, 76.30.Kg

\section{INTRODUCTION}

It is well known that the impurities of rare earth elements are an effective instrument for control of physical properties of semiconducting crystals and thin films. This was revealed from the very start of the investigations of their behavior in semiconductors (see, for example, the review articles $[1,2]$ and references therein). An important area of such investigations over a long period of time has been the study of the impurity behavior and the properties of the IV-VI semiconductors doped with rare earth impurities and their solid solutions, one of the most interesting impurities in these crystal matrices being Europium. The investigations of the electron paramagnetic resonance have shown that the Eu substitutes a metal component in the IVVI doped crystals and enters a crystal lattice in the $\mathrm{Eu}^{2+}$ charged state. The same experiments have made it possible to determine the values of g-factor as well as the coefficients of spin Hamiltonian of the $\mathrm{Eu}^{2+}$ ions in the crystal matrix of $\mathrm{Pb}(\mathrm{Sn}, \mathrm{Ge}) \mathrm{Te}(\mathrm{Se}, \mathrm{S})$ [3-7]. Since the charged state of the $\mathrm{Pb}$ ions in the $\mathrm{PbX}(X=\mathrm{Te}$, Se, and $\mathrm{S}$ ) crystals is also a $2+$ charged state [8] the doped $\mathrm{PbTe}: \mathrm{Eu}$ or $\mathrm{Pb}_{1-x} \mathrm{Eu}_{1-x} \mathrm{Te}(\mathrm{Se}, \mathrm{S})$ crystals are of the $p$-type conductivity [9-11]. The hole concentration in the doped PbTe:Eu crystals is the same as in the undoped $\mathrm{PbTe}$ ones [11]. In the semimagnetic semiconductor $\mathrm{Pb}_{1-x} \mathrm{Eu}_{x} \mathrm{Te}$, the ground state of Eu ions is split [10]. It is considered that the resulting ground state splitting of rare earth ${ }^{8} \mathrm{~S}$ ions in IV-VI crystal matrices is due to the intra-atomic $4 f-5 d$ spin-spin interaction, the spinorbit interaction for $5 d$ electrons, and their hybridization with the valence band states of the semiconductor host
$[12,13]$. The mixing of coupled conduction- and valenceband states makes the properties of rare-earth dopants sensitive to the band gap and Fermi level in the narrowgap IV-VI semiconductor host [14].

Numerous investigations of magnetization and MS have shown $[3,9,15-19]$ that it is practically impossible to grow the crystals and films of the lead and tin chalcogenides doped with Eu where the impurity enters the crystal matrix only in an isolated state. The narrow range of the doped ingots close to their end is an exception here [17]. Under usual conditions of growth of the doped crystals, at least the small complexes based on the pairs and triangles of the Eu ions are formed into the doped IV-VI:Eu crystals [3, 9, 15-19]. The origin of these complexes is likely to depend on whether $\mathrm{Eu}$ is the component of a solid solution or if it is the doping impurity in a crystal. In the first case, they are always considered to be the small inclusions of the $N N$ or $N N N$ $\mathrm{Eu}$ ions in a host crystal matrix with ferromagnetic or antiferromagnetic interaction $[3,9,15,16]$. If the $\mathrm{Eu}$ is a doping impurity in the IV-VI crystal, the situation is different. We tend to believe that in this case the mentioned small complexes are formed by the doping Eu impurity together with the background Oxygen impurity which is difficult to get rid of in the process of the doped crystal growth [17-19]. The presented paper is devoted to a further study of this problem and concentrates on the comparative investigation of the behavior of the Eu impurity into the surface and bulk layers of the doped PbTe: Eu crystals grown from melt by the Bridgman method as well as on the peculiar magnetic features in the Eu-doped PbTe single crystals. 


\section{PROBLEM STATEMENT AND MEASUREMENTS}

Generally, in the lead telluride crystals grown from the melt by the Bridgman method and doped with Eu, the impurity concentration in the surface layers is somewhat larger than the concentration in the bulk crystal. If the initial impurity concentration $N_{\text {int }}$ into the melt is very small, for example about $10^{19} \mathrm{~cm}^{-3}$, practically all the impurities can be pushed out onto the lateral surface of the crystal ingot. It is possible to establish specific conditions for the growth of a doped crystal under which the impurity behavior will be inverse to the mentioned one, i. e., the impurity will not be pushed out onto the lateral surface, but conversely will be pulled into the bulk of the crystal spreading along the doped crystals farther than usually. The characteristic longitudinal distributions of the doping impurity of Eu, which can be gotten during the growth of the doped PbTe:Eu crystals from the melt by the Bridgman method are shown in Fig. 1. The content of impurities in the doped ingots was determined by the method of roentgen fluorescent element analysis using the Expert 3L with semiconducting PIN-detector on thermoelectric cooling.

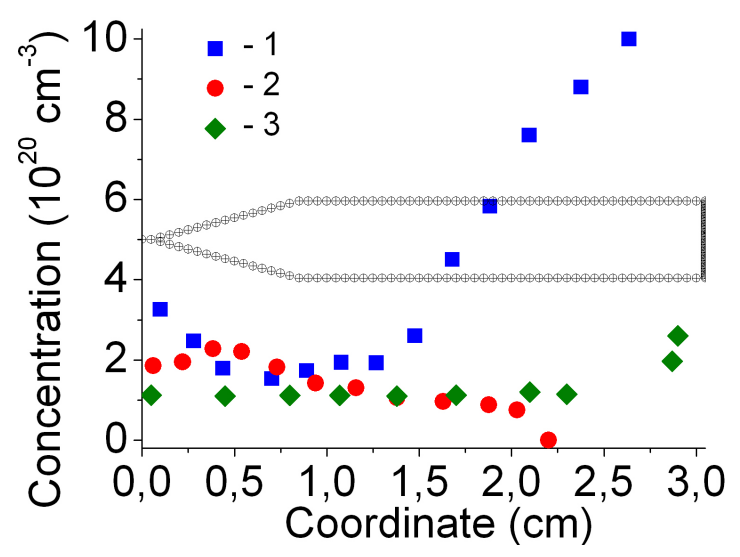

Fig. 1. The characteristic longitudinal distributions of the doping impurity of $\mathrm{Eu}$ in the doped PbTe: Eu crystals grown from the melt by the Bridgman method (the longitudinal section of the crystal ingot is shown schematically). 1 - the distribution along the lateral surface of the Ingot 1 grown from the melt with $N_{\text {imp }}=10^{19} \mathrm{~cm}^{-3} ; 2-$ the distribution along the axis of the Ingot 2 grown from the melt with $N_{\mathrm{imp}}=10^{20}$ $\mathrm{cm}^{-3} ; 3$ - the distribution along the line of the maximum concentration into the suitable cross-sections of ingot for the Ingot 3 grown under specific conditions from the melt with $N_{\text {imp }}=10^{20} \mathrm{~cm}^{-3}$.

The detailed analysis of the peculiarities of distribution of the doping Eu impurity into the PbTe: Eu crystals grown from the melt by the Bridgman method is a subject of a separate investigation and its results will be discussed more in detail elsewhere. Here we present these distributions only in order to clarify the approaches and the reasons for the choice of this or that sample for particular investigations. First of all, we have taken interest in the properties of the surface layers where the doping Eu impurity is pushed out provided its initial concentration in the melt is very small. It is impossible to fabricate the bulk samples from the surface layers of the doped ingot. Therefore the surface layers of the Ingot 1 were removed mechanically and ground to powder. Two samples were fabricated from this powder. We designate them as the Pwd $1 a$ and Pwd $1 b$ samples. Secondly, we have taken interest in the properties of the part of the doped Ingot 2 where the impurity concentration changes non-monotonously along the ingot axis and where the concentration profile has a maximum. Such an impurity distribution is impossible for any real dependences of the coefficient of segregation of the doping impurity on its concentration. Therefore, we expected to get some useful information which would help us explain such a specific behavior of the Eu impurity. For this purpose, we fabricated three samples: one of them (Pwd 2) from the incipient section of Ingot 2 before the Eu concentration maximum and the other two samples (Pwd 3 and Cr 1) from the ingot part after the mentioned maximum. The powder Pwd 2 and Pwd 3 samples were fabricated from the disks cutout across the conic part of an ingot. The crystal sample Cr 1 was fabricated from the disk cutout from the cylinder part of the ingot directly adjoining the ingot cone. Finally, we have fabricated the powder sample Pwd 4 from the end part of the Ingot 3 where we detected the impurity in a narrow range of the crystal bulk by the roentgen fluorescent element analysis. We hoped to get some beneficial information in order to compare the properties of the doped PbTe:Eu layers where the impurity is pushed out or pulled in. Magnetic measurements were performed in the temperature range $1.72-400 \mathrm{~K}$ and in applied magnetic fields up to $5 \mathrm{~T}$ using a Quantum Design MPMS-5 superconducting quantum interference device (SQUID) magnetometer.

\section{EXPERIMENTAL RESULTS}

The results of experimental investigations of both the field dependences of magnetization $M$ under the temperature $1.72 \mathrm{~K}$ and temperature dependences of paramagnetic MS in the magnetic field $B=0.1 \mathrm{~T}$ of the investigated samples are shown in Fig. 2 and Fig. 3. For greater clarity the results are presented in semilogarithmic scale.

It is evident from the presented data that the behavior of magnetization in a magnetic field is appreciably different for different groups of samples. The Pwd 2, Pwd 3, and Cr 1 samples fabricated from the Ingot 2 as well as the Pwd 4 sample are paramagnetic in the whole range of the investigated magnetic fields $0<B \leq 5 \mathrm{~T}$. At the same time, the magnetization of the first three mentioned samples increases monotonously, if $B$ increases and tends to saturation whereas the magnetization of the Pwd 4 sample starts to decrease if $B>3 \mathrm{~T}$. The Pwd $1 a$ and Pwd $1 b$ samples fabricated from the surface layers of the Ingot 1 are pronouncedly diamagnetic in the low magnetic fields $B \leq 0.07 \mathrm{~T}$ (this field range of MS is not shown 
in Figure 2 since the experimental data are presented in semilogarithmic scale). In modulo maximum, their diamagnetic magnetization reaches the value of about -0.38 $\mathrm{emu} / \mathrm{g}$. In the range of magnetic fields $0.07<B<0.1 \mathrm{~T}$, the Pwd $1 a$ and Pwd $1 b$ samples pass into paramagnetic state and their magnetization rapidly increases, if $B$ increases. If the magnetic field reaches the value of approximately $1 \mathrm{~T}$, the sample magnetization starts decreasing. In the high magnetic fields $B>4 \mathrm{~T}$, the Pwd $1 a$ sample again returns to a diamagnetic state (it is not shown in the figure for the same reason mentioned above).

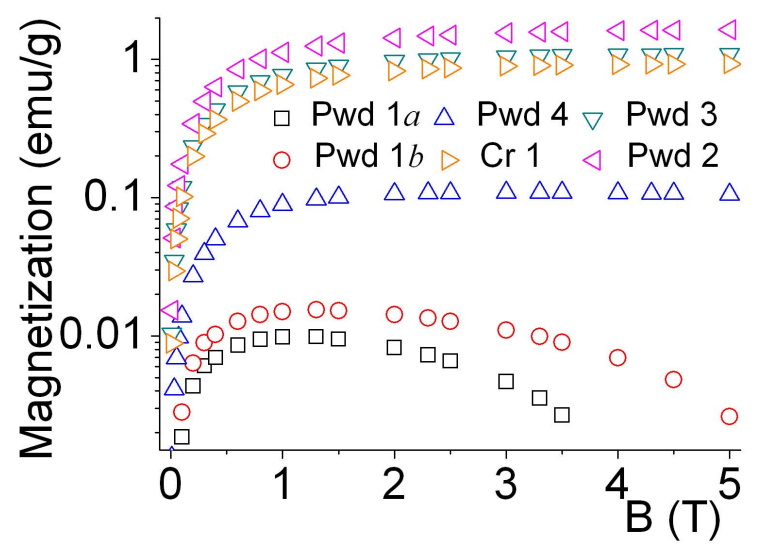

Fig. 2. Magnetization of the investigated samples vs. $B$. $T=1.72 \mathrm{~K}$.

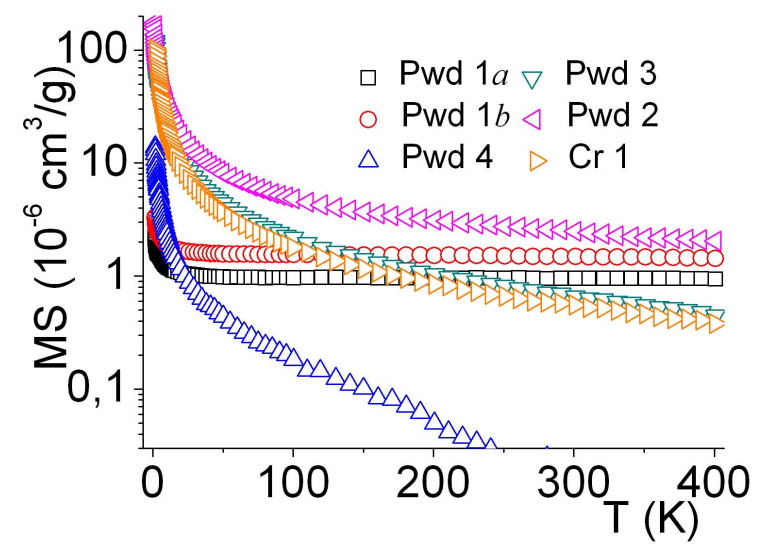

Fig. 3. MS of the investigated samples vs. T. $B=0.1 \mathrm{~T}$.
In the magnetic field $B=0.1 \mathrm{~T}$, all the samples except Pwd 4 stay in paramagnetic state in the whole range of the investigated temperatures up to $400 \mathrm{~K}$. The Pwd 4 sample passes from paramagnetic to diamagnetic state under high temperature (Fig. 3). At the same time, there are two peculiarities of temperature dependences of MS of the investigated samples which are worth emphasizring especially. The first peculiarity is the high positive values of the high temperature MS of the Pwd $1 a$ and Pwd $1 b$ samples, which are the weakest paramagnetic samples under low temperatures. Under the highest temperature $T=400 \mathrm{~K}$, the MS of these samples is close to the MS of the Pwd 2 sample whose magnetization of saturation under $T=1.72 \mathrm{~K}$ is close to a factor of a hundred more than the magnetization in the maximum of the Pwd $1 a$ and Pwd $1 b$ samples (Fig. 2). The second peculiarity is the practically full independence of the high temperature MS of the Pwd $1 a$ and Pwd $1 b$ samples of $T$ in the very wide temperature range $T$ of approximately more than $30 \mathrm{~K}$.

\section{TREATMENT OF THE EXPERIMENTAL RESULTS}

In our previous work [19] we have shown that magnetic properties of the PbTe: Eu crystals grown from the melt by the Bridgman method and doped with Eu impurity during growth under the technological conditions used in our experiments are determined according to the contribution of the single impurity centers, small clusters of the $N N$ and $N N N$ pairs of the magnetic impurities as the constituents of their complexes with the background Oxygen impurities as well as the crystal matrix. Therefore, the contribution of only these constituents will be used to quantitatively treat experimental data.

The single contribution, i. e. the contribution of the isolated ions of magnetic impurity, $M_{S}$ to the total magnetization $M$ is given [3]:

$$
M_{S}=M_{0} S_{0} x_{\mathrm{SAT}} B_{S 0}(\xi)
$$

where $M_{0}=g \mu_{\mathrm{B}} N_{\mathrm{A}} / m\left(x_{\mathrm{SAT}}\right), g$ is the Lande factor, $\mu_{\mathrm{B}}$ is the Bohr magneton, $N_{\mathrm{A}}$ is the Avogadro number, $m\left(x_{\mathrm{SAT}}\right.$ is the molar mass of the compound, $x_{\mathrm{SAT}}$ is the mole fraction of $E u^{2+}, S_{0}$ is the ion spin, $B_{S 0}(\xi)$ is the Brillouin function:

$$
B_{S 0}(\xi)=\frac{2 S_{0}+1}{2 S_{0}} \operatorname{coth}\left(\frac{2 S_{0}+1}{2 S_{0}} \xi\right)-\frac{1}{2 S_{0}} \operatorname{coth}\left(\frac{\xi}{2 S_{0}}\right),
$$

where $\xi=S_{0} g \mu_{\mathrm{B}} B / k_{\mathrm{B}} T$.

The contributions of the $N N(i=1)$ and $N N N(i=2)$ pairs $M_{P i}$ are [3]:

$$
M_{P i}=\frac{1}{2} M_{O} x_{i} \frac{\sum_{S=0}^{S_{\max }} \exp \left[\frac{J_{i}}{k_{\mathrm{B}} T} S(S+1)\right] S\left[\sinh \left[\frac{2 S+1}{2 S} \xi_{p}\right]\right] B_{S}\left(\xi_{p}\right)}{\sum_{S=0}^{S_{\max }} \exp \left[\frac{J_{i}}{k_{\mathrm{B}} T} S(S+1)\right]\left[\sinh \left[\frac{2 S+1}{2 S} \xi_{p}\right]\right]}, \quad i=1,2,
$$


where $\xi_{p}=S g \mu_{\mathrm{B}} B / k_{\mathrm{B}} T$ i $S_{\max }=2 S_{0}, J_{i}$ are the integrals of ferromagnetic $(i=1)$ and antiferromagnetic $(i=2)$ interaction between the $N N$ and $N N N \mathrm{Eu}^{2+}$ ions, respectively.

The total magnetization of the doped samples in the magnetic field $H$ was calculated as:

$$
M=M_{S}+M_{P 1}+M_{P 2}+\chi_{\text {Matrix }}(0) H,
$$

where $\chi_{\text {Matrix }}(0)$ is the MS of the crystal matrix under the condition $T>0 \mathrm{~K}$.

The total MS of the doped samples $\chi_{\mathrm{d}}(\mathrm{Eu})$ was calculated as:

$$
\chi_{\mathrm{d}}(E u)=\chi_{\text {Matrix }}+\chi_{\mathrm{Eu}},
$$

where $\chi_{\text {Matrix }}$ is the MS of both the crystal matrix of the undoped crystals and a free carrier of the charge; $\chi_{\mathrm{Eu}}$ is the sum of the MS of the different mentioned magnetic centers of Eu:

$$
\chi_{\mathrm{Eu}}=\chi_{S}+\chi_{P 1}+\chi_{P 2} .
$$

$\chi_{\text {Matrix }}$ can be written as [20]:

$$
\chi_{\text {Matrix }}(T)=\chi_{\text {re }}+\chi_{\mathrm{sp}}(n, T),
$$

where $\chi_{\mathrm{sp}}$ is a special constituent of MS, which depends on the free carrier concentration $n$ and temperature $T$, and $\chi_{\mathrm{re}}$ is the regular constituent of MS which does not depend on $n$ and $T$ being the adjustable parameter of the theory. Thus:

$$
\chi_{\text {Matrix }}(0)=\chi_{\text {re }}+\chi_{\mathrm{sp}}(n, 0) .
$$

Thus, the $\chi_{\mathrm{d}}(\mathrm{Eu})$ can be calculated as:

$$
\chi_{d}(\mathrm{Eu})=\chi_{\mathrm{Eu}}+\chi_{\text {Matrix }}(0)+f_{n}(T),
$$

where the form of the $f_{n}(T)$ function depends on the free carrier concentration $n$.

\begin{tabular}{|c|c|c|c|c|c|c|}
\hline The samples & \multicolumn{5}{|c|}{ The parameters } \\
\hline & $N_{\mathrm{Eu}}\left(\right.$ Singles), $\mathrm{cm}^{-3}$ & $N_{\mathrm{Eu}}(N N$ pairs $), \mathrm{cm}^{-3}$ & $N_{\mathrm{Eu}}(N N N$ pairs $), \mathrm{cm}^{-3}$ & $N_{\mathrm{Eu}}($ Total $), \mathrm{cm}^{-3}$ & $\chi_{\mathrm{Matrix}}(0), 10^{-6} \mathrm{~cm}^{3} / \mathrm{g}$ \\
\hline & & & & & For LT $M(B)$ & For HT $\chi(T)$ \\
\hline Pwd 2 & $6.1 \cdot 10^{19}$ & $8.0 \cdot 10^{19}$ & $5.9 \cdot 10^{19}$ & $2.0 \cdot 10^{20}$ & +1.47 & +1.47 \\
\hline Pwd 3 & $4.8 \cdot 10^{19}$ & $5.2 \cdot 10^{19}$ & $4.4 \cdot 10^{19}$ & $1.44 \cdot 10^{20}$ & -0.1 & -0.1 \\
\hline Cr 1 & $4.0 \cdot 10^{19}$ & $4.3 \cdot 10^{19}$ & $3.6 \cdot 10^{19}$ & $1.19 \cdot 10^{20}$ & -0.14 & -0.14 \\
\hline Pwd $1 a$ & 0 & $2.0 \cdot 10^{18}$ & $2.7 \cdot 10^{17}$ & $2.27 \cdot 10^{18}$ & -0.44 & +0.93 \\
\hline Pwd $1 b$ & 0 & $2.84 \cdot 10^{18}$ & $3.5 \cdot 10^{17}$ & $3.19 \cdot 10^{18}$ & -0.45 & +1.46 \\
\hline Pwd 4 & $1.2 \cdot 10^{19}$ & $2.2 \cdot 10^{18}$ & $1.2 \cdot 10^{18}$ & $1.54 \cdot 10^{19}$ & -0.33 & -0.075 \\
\hline
\end{tabular}

Table 1. The parameter values used for calculation of the low temperature (LT) magnetization $M(B)$ and the high temperature (HT) MS $\chi(T)$ of the investigated samples.

As we have alluded [11], the PbTe crystals doped with $\mathrm{Eu}$ in a wide range of the concentration of the doping impurity have got the hole concentration about $(2 \div 3) \cdot 10^{18}$ $\mathrm{cm}^{-3}$, i. e., practically the same as the undoped PbTe crystals grown from the melt by the Bridgman method. For such hole concentration, $f_{n}(T)$ can be approximated as [19]:

$$
f_{n}(T)=2.5 \cdot 10^{-4} T-2.4 \cdot 10^{-7} T^{2}
$$

To calculate $M_{P 1}, M_{P 2}, \chi_{P 1}$, and $\chi_{P 2}$ we have used the values of the exchange integrals between the $E u^{2+}$ ions as the constituents of the complexes of the magnetic impurities with the Oxygen ones in the crystal matrix of lead telluride obtained in [19]: $J_{1} k_{\mathrm{B}}=+0.056 \mathrm{~K}$, $J_{2} / k_{\mathrm{B}}=-0.13 \mathrm{~K}$. The Eu concentrations forming different impurity complexes as well as the parameter $\chi_{\text {Matrix }}(0)$ were the adjustable parameters of fitting. Their values that provide the best reproduction of the experimental dependences $M(B)$ and $\chi(T)$ by the calculated ones are presented in Table 1.

It is obvious from the data in Table 1 that only for the Pwd 2, Pwd 3, and Cr 1 samples fabricated from the bulk part of the Ingot 2, both the magnetization field dependence and the MS temperature dependence can be well described by the same set of parameters for each sample. The comparison of the experimental and of the calculated data by the example of the Pwd 3 and $\mathrm{Cr}$ 1 samples that possess nearly equal total Eu impurity concentration is shown in Fig. 4.

For the other three samples, especially for the Pwd $1 a$ and $\mathrm{Pwd} 1 b$ samples, fabricated from surface layers of the Ingot 1, the situation is principally different. Only the same set of concentration of different Eu centers can be used to quantitatively describe the $M(B)$ and $\chi_{d}(T)$ dependences for each sample. At the same time, the $\chi_{\text {Matrix }}(0)$ values for magnetization and MS are incredibly different not only in value but also in sign. The magnetic behavior of the Pwd 4 sample is intermediate between the behaviors of the two mentioned groups of samples. It cannot be described by the same value $\chi_{\text {Matrix }}(0)$ for $M$ and $\chi_{d}$ as for the samples fabricated from the bulk of the incipient part of Ingot 2 but the discrepancy between the $\chi_{\text {Matrix }}(0)$ values required for the reproduction of low temperature magnetization and of high temperature MS is not so considerable as for the samples fabricated from the surface layers of the Ingot 1 (Table 1). The comparison of the experimental and calculated $M(B)$ dependences for this group of the samples is shown in Fig. 5. 

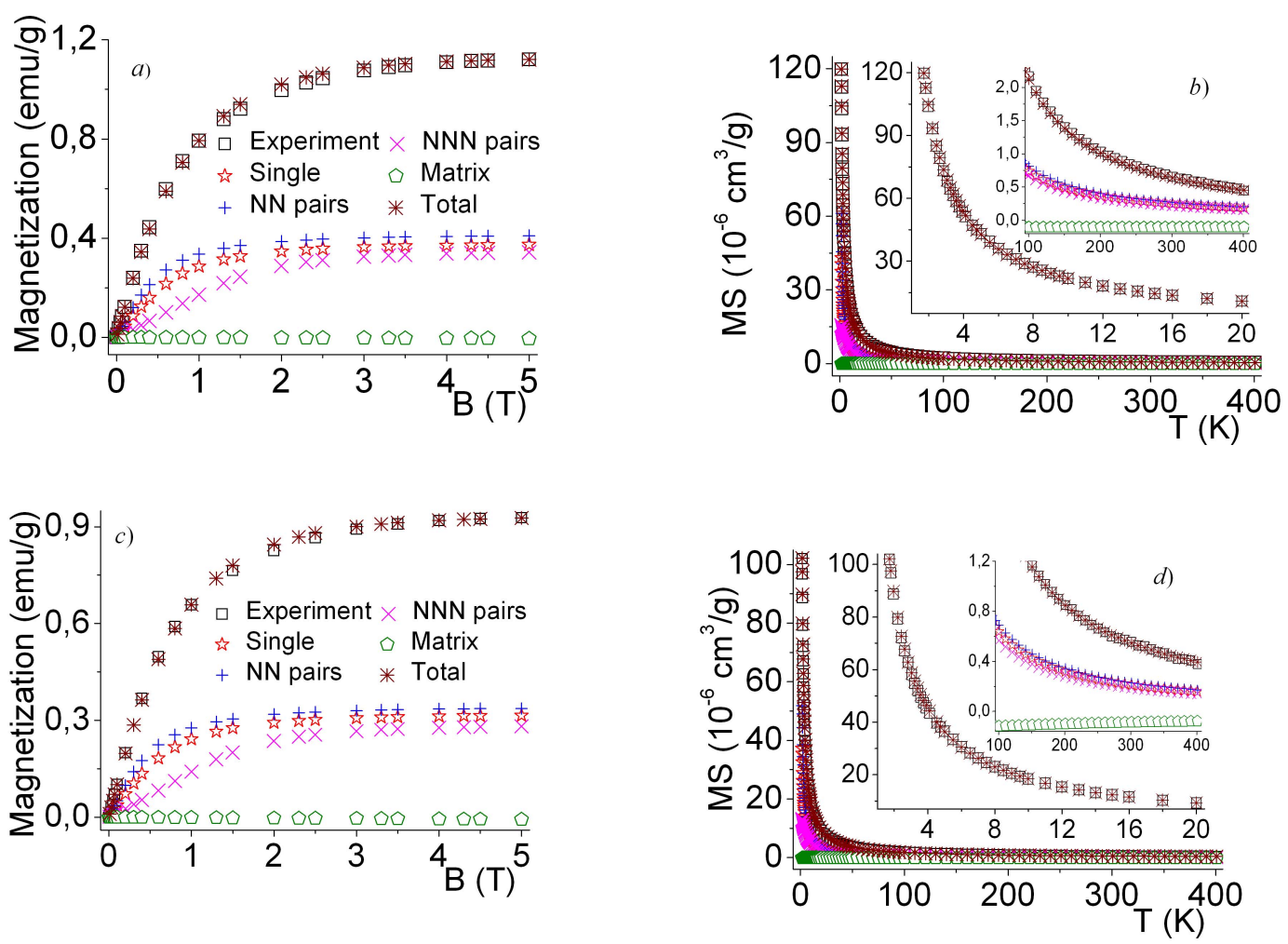

Fig. 4. Magnetization vs. $B$ under $T=1.72 \mathrm{~K}$ and MS vs. $T$ under $B=0.1 \mathrm{~T}$ for the Pwd $3(a, b)$ and Cr $1(c, d)$ samples. The insets show the fragments of the low and high temperature MS of the samples. The designations for MS are the same as for magnetization.
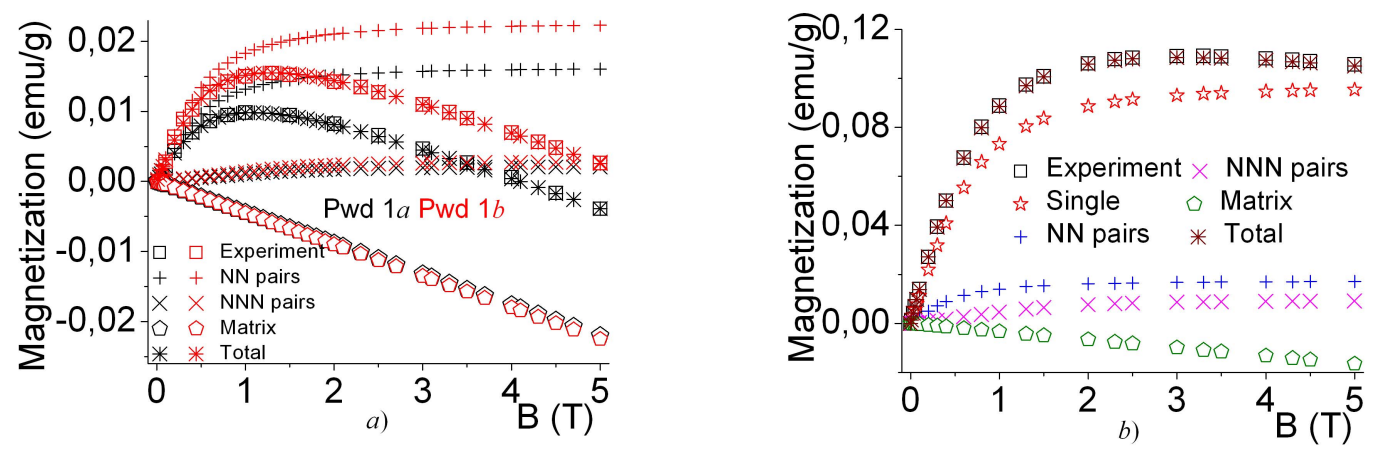

Fig. 5. Magnetization vs. $B$ under $T=1.72$ K.a) The Pwd $1 a$ and Pwd $1 b$ samples. $b$ ) The Pwd 4 sample.

\section{DISCUSSION}

Let us briefly discuss the most important results.

The Pwd 2, Pwd 3, and Cr 1 samples: the most important are the ratios between the concentration of single $\mathrm{Eu}^{2+}$ centers and the ions forming the impurity pairs in different samples as well as the differences of temperature dependences of the constituents $\chi_{\text {Matrix }}$ in the crystal and powder samples.

As follows from Table 1, in the three investigated samples fabricated from the initial part of the doped Ingot 2, the concentration of the $\mathrm{Eu}$ ions in pairs constitutes approximately two thirds of the to- tal impurity concentration. The ratio $\left[N_{\mathrm{Eu}}(\mathrm{NN}\right.$ pairs $)$ $+N_{\mathrm{Eu}}(N N N$ pairs $) / N_{\mathrm{Eu}}$ (Total)] decreases monotonously towards the ingot's end from value of $69.5 \%$ for the Pwd 2 sample to that of $66.4 \%$ for the Cr 1 sample. This corroborates our previous data and conclusions [19] concerning the regularity of the distribution of the small $\mathrm{Eu}$ complexes in the doped PbTe:Eu crystals and their origin as the complexes of the doping impurities of Europium and background impurities of Oxygen. On the other hand, this result shows that it is necessary to take into consideration the interaction between the mentioned impurities during the process of the doped crystal growth in order to rightly interpret the regularity of the distri- 
bution of the Eu impurity into the PbTe:Eu ingots grown from the melt by the Bridgman method.

From the insets in Fig. $4 b$ and Fig. $4 d$ one can see the fundamental difference between the dependences of MS on $T$ for crystal and powder samples. In order to rich a full matching of the calculated dependence $\chi_{d}(T)$ with the experimental one, in the first case it is necessary to consider the constituent $\chi_{\text {Matrix }}$ of the total MS of the sample dependent on $T$ (Fig. $4 d$ ), whereas in the second case it does not depend on $T$ (Fig. $4 b$ ). The same regularity holds for all the investigated powder samples. The differences of the temperature dependences of $\chi_{\text {Matrix }}$ for crystal and powder samples are explained by the different conditions for electroconductivity. A powder sample is a sharply nonhomogeneous system. It consists of conductive crystal grains separated by the potential barrier formed by both the surface of the grains and the dielectric spaces between the grains. Hence, as regards energy, a powder sample is a disordered system of potential wells separated by high potential barriers where the free carriers are localized in the deepest wells. The concentration of carriers having an energy higher than the percolation level that can move freely across a sample is very small. Correspondingly, the free carrier contribution to the total MS of the powder samples declines sharply. The contribution of the crystal matrix is formed both by the Langevin diamagnetic and Van Vleck paramagnetic constituents of the ion frames of the crystal lattice which do not depend on temperature [21]. Therefore, the constituent of the MS of the powder samples, which does not relate to the Eu impurity, does not depend on $T$.

The Pwd $1 a$ and Pwd $1 b$ samples: these samples fabricated from the surface layers of the Ingot 1 have the most peculiar magnetic features among the other Eu-doped PbTe samples, i.e., the clearly expressed low temperature diamagnetism in the low magnetic fields $B \leq 0.07 \mathrm{~T}$, the strong high temperature paramagnetism practically independent of temperature in the range of $T$ approximately more than $30 K$ (Fig. 3), and a very large divergence between the $\chi_{\text {Matrix }}(0)$ values necessary for quantitative description of the dependences of the low temperature magnetization $M(B)$ and the high temperature MS $\chi_{d}(T)$, which concerns both the value and sign of the parameter (Table 1).

In order to describe the $M(B)$ dependences under temperature $T=1.72 \mathrm{~K}$, the $\chi_{\text {Matrix }}(0)$ parameter should be equal to $-0.44 \cdot 10^{-6}$ and $-0.45 \cdot 10^{-6} \mathrm{~cm}^{3} / \mathrm{g}$ whereas to explain the $\chi_{d}(T)$ high temperature dependences it should be equal to $+0.93 \cdot 10^{-6}$ and $+1.46 \cdot 10^{-6} \mathrm{~cm}^{3} / \mathrm{g}$ for the Pwd $1 a$ and Pwd $1 b$ samples, respectively. In other words, the crystal matrix of these powders is greatly diamagnetic under the low temperature $T=1.72 \mathrm{~K}$ and strongly paramagnetic under high temperature, and its paramagnetic susceptibility practically does not depend on $T$ in this temperature range. There is another impor- tant result of a quantitative treatment of experimental data for these samples that deserve to be specially mentioned: the samples fabricated from the surface layers of Ingot 1 do not contain single centers of Eu impurity.

The strong diamagnetism of the surface samples and its origin is a subject of a separate investigation and its results will be discussed more in detail elsewhere. Here we would like to pay attention to the large positive values of the $\chi_{\text {Matrix }}$ parameter of the Pwd $1 a$ and Pwd $1 b$ samples as well as of the Pwd 2 sample. In our previous works $[19,22]$ we explained the changes of $\chi_{\text {Matrix }}$ by the effect of the defects on symmetry of distribution of the electron density of the frame of the crystal lattice which causes an increase of the Van Vleck paramagnetic constituent of the lattice MS. From this standpoint, the obtained data show that both the surface of the doped crystal ingots and their initial sections are the most defective parts of the crystals doped with Eu impurity.

\section{CONCLUSIONS}

The magnetization and magnetic susceptibility of the bulk and surface layers of the PbTe:Eu doped crystals grown from the melt by the Bridgman method are investigated. The main investigations were carried out on the powder samples and one crystal sample was used for the comparative analysis.

It is shown that the magnetic properties of the investigated samples can be described very well by the contribution of the single $\mathrm{Eu}^{2+}$ centers, the small clusters of the NN and NNN pairs of the magnetic impurities as the constituents of their complexes with the background Oxygen impurities as well as the crystal matrix. The ratios between the concentration of single $\mathrm{Eu}^{2+}$ centers and the ions forming the impurity pairs is different in different positions of the crystal bulk as well as in the bulk and surface samples. It is concluded that both the surface of the doped crystal ingots and their initial sections are the most defective parts of the PbTe crystals doped with Eu impurity.

It is revealed that a strong paramagnetism of the surface layers is practically independent of $T$ in the temperature range over $30 \mathrm{~K}$. It is revealed also that the contribution of the matrix of the crystal grains to the total MS of the doped powder samples does not depend on temperature in contrast to the crystal samples where this constituent of the total MS depends appreciably on $T$. These differences of the behavior of the MS of the crystal and powder samples are explained by the lack of the free carriers in the disordered powder samples with the energy higher than the percolation level which causes the lack of the free carrier contribution into MS of the crystal matrix and its independence of temperature. 
[1] H. Ennen, J. Schneider, J. Electron. Mater. 13, 114 (1984).

[2] V. F. Masterov, Fiz. Tekh. Polupr. 27, 1435 (1993).

[3] S. Isber, S. Charar, C. Fau, V. Mathet, M. Averous, Z. Golacki Phys. Rev. B 52, 1678 (1995).

[4] S. K. Misra et al., J. Phys.: Condens. Matter. 7, 9897 (1995).

[5] X. Gratens, S. Isber, S. Charar, Phys. Rev. B 76, 035203 (2007).

[6] S. Isber, S. K. Misra, S. Charar, X. Gratens, M. Averous, Z. Golacki, Phys. Rev. B 56, 13724 (1997).

[7] T. Radzynski, A. Lusakowski, K. Swiatek, T. Story, J. Phys.: Condens. Matter. 21, 405802 (2009).

[8] G. Nimtz, B. Schlicht, Narrow-gap semiconductors (Springer, Berlin, 1983), p. 1.

[9] M. Gorska, J. R. Anderson, G. Kido, Z. Golacki, Sol. State Communs 75, 363 (1990).

[10] M. Gorska, A. Lusakowski, A. Jedrzejczak, Z. Golacki, R. R. Galazka, J. R. Anderson, H. Balci, Phys. Rev. B 73, 125201 (2006).

[11] D. M. Zayachuk, V. I. Mikityuk, Ye. O. Polyhach, V. E. Slynko, O. G. Khandozhko, V. V. Shlemkevych,
Phys. Chem. Sol. State 10, 272 (2009).

[12] A. Lusakowski, Phys. Rev. B 72, 094429 (2005).

[13] A. Lusakowski, M. Gorska, J. R. Anderson, Y. Dagan, Z. Golacki, J. Phys.: Condens. Matter 21, 265802 (2009).

[14] V. K. Dugaev, V. I. Litvinov, A. Lusakowski, Phys. Rev. B 59, 15190 (1999).

[15] M. Gorska, J. R. Anderson, J. L. Peng, Y. Oka, J. Y. Jen, I. Mogi, D. Ravot, Z. Golacki, Phys. Rev. B 55, 4400 (1997).

[16] X. Gratens, E. ter Haar, V. Bindilatti, N. F. Jr. Oliveira, Y. Shapira, M. T. Liu, Z. Golacki, S. Charar, A. Errebbahi, J. Phys.: Condens. Matter 12, 3711 (2000).

[17] D. M. Zayachuk, V. I. Mikityuk, V. M. Frasunyak, V. V. Shlemkevych, J. Cryst Growth 311, 4670 (2009).

[18] D. M. Zayachuk, J. Magn. Magn. Mater. 322, 60 (2010).

[19] D. M. Zayachuk, V. I. Mikityuk, V. V. Shlemkevych, D. Kaczorowski, J. Cryst Growth (2011), in press.

[20] L. A. Falkovskii, A. V. Brodovoi, G. V. Lashkariov, J. Experim. Theor. Phys. 80, 334 (1981).

[21] S. V. Vonsovskii, Magnetizm (Wiley, New York, 1974).

[22] P. M. Starik, V. I. Mikityuk, D. M. Zayachuk, R. D. Ivanchuk, Fiz. Tekh. Polupr. 18, 2101 (1984).

\title{
ОСОБЛИВОСТІ МАГНІТНИХ ВЛАСТИВОСТЕЙ МОНОКРИСТАЛІВ ТЕЛУРИДУ СВИНЦЮ, ЛЕГОВАНИХ ДОМІШКОЮ ЕВРОПІЮ
}

\author{
Д. М. Заячук ${ }^{1}$, В. І. Микитюк ${ }^{2}$, А. В. Пашук ${ }^{1}$, В. В. Шлемкевич ${ }^{2}$, К. С. Ульяницький ${ }^{2}$, Д. Качоровскі $^{3}$ \\ ${ }^{1}$ Національний університет "Львівсъка політехніка", вул. Степана Бандери, 12, Львів, 79013, Україна, \\ ${ }^{2}$ Чернівецький національний університет, вул. Кочюбинсъкого, 2, Чернівці, 58012, Украӥна, \\ ${ }^{3}$ Інститут низъкотемпературних і структурних дослідженъ, Польсъка академія наук, \\ 50-950, Врочлав, 1410, Польща
}

Досліджено намагніченість $M$ за температури $1.72 \mathrm{~K}$ в діапазоні магнітних полів В 0-5 Тл та магнітну сприйнятливість (MC) $\chi$ у магнітному полі 0.1 Тл в температурному інтервалі $1.7-400 \mathrm{~K}$ порошкових та кристалічних зразків $\mathrm{PbTe:Eu,} \mathrm{виготовлених} \mathrm{з} \mathrm{об'ємної} \mathrm{частини} \mathrm{та} \mathrm{поверхневих} \mathrm{шарів} \mathrm{леґованих} \mathrm{зливків,}$ вирощених із розплаву методом Бріджмена. Виявлено низку особливостей магнітних властивостей кристалів $\mathrm{PbTe}$, леґованих $\mathrm{Eu}$, таких, як: значні відмінності між намагніченістю і МС поверхні й об'єму леґованих зливків $\mathrm{PbTe:Eu;} \mathrm{сильний} \mathrm{парамагнетизм} \mathrm{поверхневих} \mathrm{шарів,} \mathrm{що} \mathrm{практично} \mathrm{не} \mathrm{залежить} \mathrm{від} T$ в області температур, вищих за $30 \mathrm{~K}$; принципові розходження між температурними залежностями МС кристалічної матриці леґованих порошкових і кристалічних зразків. Проаналізовано можливі механізми виникнення виявлених особливостей магнітних властивостей різних порошкових і кристалічних зразків. 